\title{
"Chief, I think we can make this work." Perceptions of successes and failures in technology implementation from Canadian police leaders
}

\author{
James Brown* and Michael Doucet ${ }^{\dagger}$
}

\begin{abstract}
This article looks at the pressures, issues, and organizational elements that were perceived to have the greatest impact on the success or failure of technology projects, based on discussions with police leaders who have recently retired from police organizations across Canada. These discussions were technology-agnostic and focused on the human dimension of technology projects to understand what worked, what didn't, and why, with the intent to help inform the discussion on technology acquisition for today's police leaders.
\end{abstract}

Key Words Policing and technology; police leadership and technology; technology projects.

\section{INTRODUCTION}

In today's technology-rich environment, police leaders are constantly confronted with technology issues, from replacement technology for existing tasks to new technology that may address emerging issues. Regardless of the technology involved, its impact, scope, or cost, police leaders and their teams must evaluate, manage, and integrate the technology assessment, acquisition, and implementation experience, ultimately leading their organizations through it and addressing the question, "Will this work for us?" The police leaders who were consulted during this study unanimously agreed on the need for strategic alignment and effective organizational leadership for technology projects and programs to be successfully implemented. Irrespective of the size of the organization or the scope of the technology involved, they agreed that successful leaders created a clear vision of what success looked like and how the technology supported their policing philosophy and aligned with their organizational strategy. These leaders were clear in the expression of their expectations and they managed and monitored their resources to ensure time and cost control. Most importantly, police leaders articulated their need to ensure that new technology projects were ethical in their design and scope while impacting positively on the communities they served.

During the discussion, a number of key issues arose that were consistently identified as critical elements. We have condensed these elements into six pillars of focus that police leaders should consider when implementing new technology or initiating a technology project (Table I).

\section{BACKGROUND}

In June of 2020, the authors were working with privatesector corporations seeking to support police services across Canada. As both authors had a wide range of experience in technology projects and their implementation in policing environments in Canada, questions arose about how police leaders have historically addressed technology and technology projects. Academic and government-funded research reports and journal articles had identified some of the challenges associated with police and technology. The authors were mindful that "with a greater reliance on technology in society comes a greater technology presence in police work" (Rogers \& Scally, 2017, p. 101). In order to learn more about the thought processes, pressures, and expectations involved in technology decisions, as well as the perceptions of success and failure, the authors undertook an online (remote) dual-moderator group discussion with a series of recently retired police leaders from across Canada. All of the participants had served as either chief or command-level staff within policing services in Canada (see Table II). Each of the participants was still engaged in supporting community safety and well-being, and each would

Correspondence to: James Brown, Ontario Tech University, 2000 Simcoe St. N., Oshawa, ON L1G OC5.

E-mail: james.brown@uoit.ca

To cite: Brown, J., Doucet, M. (2020). "Chief, I think we can make this work." Perceptions of successes and failures in technology implementation from Canadian police leaders. Journal of Community Safety and Well-Being, 5(4), 171-177. https://doi.org/10.35502/jcswb.157

(C) Author(s) 2020. Open Access. This work is distributed under the Creative Commons BY-NC-ND license. For commercial re-use, please contact sales@sgpublishing.ca.

gPUBLISHING Published by SG Publishing Inc. CSRA Official publication of the Community Safety Knowledge Alliance. 
self-identify as a reform-minded police leader. The consultation process started with a series of questions provided to participants, followed by an online discussion forum with all participants, who were then invited to comment on this paper as it evolved.

\section{QUESTIONS FOR PARTICIPANTS}

The research authors designed a series of questions for the forum participants that were designed to start the discussion. Questions were provided two days prior to the forum, and

TABLE I Six pillars of focus and related questions based on emerging issues cited by research participants

\section{Strategic alignment}

Do we have a technology strategy?

Does the technology support our policing philosophy?

Is the technology aligned with our strategic vision?

How does the technology support our mission and/or vision?

Is this technology consistent with what the public would expect of us?

Are there any ethical considerations in the implementation of this technology, including information security and privacy issues?

Is this technology initiative being driven by our strategic vision, or is our strategy being modified to align with the technology?

\section{Ensuring adequate technology resources}

Does the organization have access to sufficient technology resources and does it have the skills required for the project or initiative?

Does the organization have staff who are fulfilling the role of Chief Information Officer (CIO), Chief Technology Officer (CTO) and/ or Chief Information Security Officer (CISO)?

Do those responsible for information technology know what is expected of them?

Do those responsible for information technology have the knowledge, skills and abilities to perform to the expectations?

How are skills enhanced over time?

\section{Managing expectations}

What does the executive team expect from this technology initiative?

What do the impacted stakeholders (anticipated users) expect from this initiative?

What does the Board or Council expect from this initiative?

What does or should the public expect from this initiative?

What does the project implementation team expect from this initiative?

Are all of the expectations aligned?

How do you ensure and measure alignment?

\section{Defining success}

What problem or opportunity is the technology project intended to solve?

What should the organization (operating environment) look like after successful implementation?

How should success be measured and reported on?

How should the technology project positively impact the community served?

Once implemented, has the organization committed to operational funding to support the capability?

\section{Giving consideration to technology debt}

Does this technology acquisition add to a legacy system? If so, should the organization continue to add (invest) in the sunken technology costs?

Is this technology initiative/application one that is continuing to evolve, or should the organization be looking for alternatives?

Is the organization selecting this technology because current training and skill sets for IT and/or field personnel are not adversely impacted, or should the organization be looking at alternatives?

If the organization selects an alternative technology or methodology, what are the impacts?

Can the technology acquisition retire existing capabilities?

\section{Customization versus configuration}

Does the technology fulfill our need?

Should or could the organization partner with other agencies (police or municipal) which would benefit from the technology while sharing costs (and/or resources)?

Does the organization need customized software, or does existing software need to be configured to meet the organization's needs? 
TABLE II Forum participants (retired from position indicated)

\begin{tabular}{lcc}
\hline \multicolumn{1}{c}{ Name } & Title & Police service \\
\hline Paul Beesley & Chief Superintendent & Ontario Provincial Police (ON) \\
Jean-Michel Blais & Chief & Halifax Regional Police Service (NS) \\
& Chief Superintendent & RCMP \\
Devon Clunis & Chief & Winnipeg Police Service (MB) \\
Kim Derry & Deputy Chief & Toronto Police Service (ON) \\
Geoffrey Nelson & Chief & Brantford Police Service (ON) \\
Murray Rodd & Chief & Peterborough Police Service (ON) \\
Matthew Torigian & Chief & Waterloo Regional Police Service (ON) \\
& Deputy Solicitor General & Ontario \\
\hline
\end{tabular}

the participants were told that the questions were intended to elicit input rather than being rigid or prescriptive.

\section{Setting the Stage}

At the beginning of the discussion, we identified a series of issues that we believe have been challenging to police executives for many years and which we relayed to participants verbally. This included comments about frequent resource shortages; compounding technical debt in technical product acquisition; changes in organizations' digital transformation and their use of cloud computing; new and emerging issues surrounding work from home and business continuity; the continuing growth in complexity of technology and, finally, the issues surrounding any technology program and board communication.

Historically, "technology [has] often [been] placed into categories in order to better understand its function. In the policing sphere, Manning used five different areas to explain police technology: communicative, mobility, transformative, training and analytical" (Rogers \& Scally, 2017, p. 101). We did not separate technology acquisition during this discussion, nor did we seek input in different categories of technology; instead, we focused on technology acquisition as a singular element within the spectrum of leadership responsibilities.

\section{Questions}

The following questions were posed to the discussion group participants. This resulted in a free-flowing conversation in which a number of topics were addressed. As a result, the comments presented in this paper are a synthesis of the discussions on all of these topics rather than answers to each question.

What are the top three technology challenges that you faced while serving in your senior leadership role?

What were your greatest challenges in technology during your tenure in leading a police service?

What do you perceive as your greatest successes in technology?

What do you perceive your greatest disappointments were in technology?

- What technology undertaking or project surpassed your expectations (and why)?

- In the field of technology, what would you say your "hot buttons" were?
What changes would you want in the technology project process?

What are the top three areas in technology that you feel need to be the focus for greater understanding by police leaders?

What do you feel should be the future of technology discussion points for police leaders?

- If you had three pieces of advice for today's police leaders related to technology, what would they be?

\section{FINDINGS}

The findings of this research represent the consensus of the participants based on their years of experience in leading diverse policing organizations in a number of provinces. Having such a diverse group collaboratively identify the following key elements and reach agreement as to their priority underscores their universal importance, certainly in the Canadian policing context. It was the hope of the research team that the identification of these key elements could serve as a template or framework for today's police leaders as they endeavour to implement new technologies in their policing organizations.

Throughout this process, moderated by the authors, the conversation was dynamic and flexible. Participants did not hesitate to introduce new issues arising from previous speakers' topics, nor did they exhibit any inhibition in discussing issues. They did not appear reluctant to address any topic, success, or failure.

While this process was focused on Canadian policing issues with Canadian police leaders, the issue of technology and policing is an international one. In 2017, the U.S. National Institute of Justice sponsored a report that was co-authored by the Police Executive Research Forum. That report concluded that

as a whole, our findings demonstrate that law enforcement technology adoption is often ad hoc and not based on longer-term planning. The tendency to purchase technology without a clear, strategic plan can result in limited integration within the agency and a failure to recognize the primary or secondary benefits of the technology. These factors can lead to disillusionment and a lack of continuation funding for maintaining or updating particular types of technology. (Strom et al., 2017, pp. 2-3) 
Those findings were reflected in the opinions, comments and insights of this discussion group.

\section{Strategic Alignment}

The issue of technology alignment with the organizational strategy and goals came up early and frequently in the discussion, and, according to the participant group, this was the single most important issue determining success in technology acquisition and implementation. At the same time, the participants acknowledged that this was also the most challenging element of technology, with a prevalent perception among the participants that it was frequently the technology "tail" that was wagging the operational "dog"; in other words, organizational strategies were driven by available technology.

While participants acknowledged that their Information Technology (IT) operations had developed an IT strategy that was reflective of the IT needs of the organization, they felt that there was a need for a technology strategy at the command level to address the operational technology needs of the organization, and that the acquisition of technology needed to be aligned with the organizational goals, mission, and strategy.

This issue is neither new nor peculiar to Canadian police services. The 2017 National Institute of Justice report found that

in general, across U.S. [law enforcement agencies], a strong association between policing strategy and technology uses was not found. In other words, at a national level, agencies are not making decisions to acquire technology based on dominant policing philosophies or the activities they prioritize. Instead, agencies appear to adopt technology ad hoc in response to a constellation of factors that includes executive staff decisions, perceived needs, community demands, and available funding. (Strom et al., 2017, p. 1)

The report concluded that "as the rate of technology adoption accelerates, it becomes increasingly important for police agencies to consider how they select and implement technology and what strategic objectives these technologies will help them achieve" (Strom et al., 2017, pp. 2-3).

The discussion group also identified the misalignment of applications with expectations at this stage of technology acquisition, with one of the participants acknowledging that the organization had used data that had been collected for a different purpose than the application intended, and, as a result, the analysis results were inconsistent with the reality that the service was experiencing.

This challenge was reinforced by previous research undertaken by Rogers and Scally in which they echoed Strom, stating that

a further problem for the introduction of technologies into the police organisation is a tendency to attempt to fit new systems into existing structures instead of developing technology structures to support new and innovative methods of police work. This means that the police use the new technology in 'traditional ways' rather than using it for its intended or any enlightened purpose. (Rogers \& Scally, 2017)

\section{Managing Expectations}

Discussion group participants also recognized that, while there are many stakeholders in a technology project, there is a need to both understand and "level set" or manage the expectations of the various stakeholders, which may be drastically misaligned. The role of the organizational leadership is to ensure that there is alignment among the various stakeholders to avoid projects where "agencies may implement and use technology without having sound evidence about its efficacy" (Strom et al., 2017, pp. 4-14).

\section{Defining Success}

Prior to the decision to acquire a technology or a service or to commence a technology project, as the discussion group participants noted, there is a need to both understand related organizational challenges and articulate the specific problem the technical solution was intended to solve or the opportunity the technology expected to address. They also acknowledged that police leaders should be able to articulate a compelling vision of what the operating environment would be like following the successful implementation of the technology. Participants also identified the need to establish success measures and how technology projects will be reported on prior to the start of a technology project. Perhaps most important to the group was the question of how the technology will positively impact the community that is being served to avoid the U.S. experience in which "results from site data suggest that technology is often implemented without a clear plan to measure the technology's success or impact" (Strom et al., 2017, pp. 3-4).

\section{Acknowledging Technology Debt (Legacy Systems and Infrastructure)}

Discussion participants acknowledged that they found they were frequently constrained in their technology acquisition by either their legacy infrastructure or the technology cooperative in which they participated. While they recognized that it was frequently necessary to continue to invest in legacy infrastructure, they also advocated for chief executives to be mindful of the rationale for continued investment.

\section{Customization and Configuration}

The discussion group participants agreed that technology customization for their respective environments was an ongoing challenge. They found that long delays in customization resulted in serious lag time for project completion, or that proposed technology solutions did not fit with their environments. Equally, for those services in technology cooperatives, they found that limitations to configuration left them searching for alternative technological solutions when a solution existed that they were unable to implement due to constraints within the cooperative.

\section{Appropriate Technology Resources}

While having technically competent resources to undertake a technology project was considered essential, the discussion participants identified the need to ensure that a senior position in the organization was responsible for the security of the organization's information. The cyber environment has evolved so drastically that specialized resources are not always available within each service. The creation of a chief information security officer (CISO) position working at the command level of the 
police service was identified as a best practice endeavour worthy of replication. It was identified as being much more than a job title and required a knowledgeable and skilled practitioner who could advise the command team on decisions around technology. Equally, the position is needed to advise the executive management on other aspects of information and data security and privacy, including but not limited to risks surrounding physical-plant security, external access to data, data sharing, and legal issues connected with the data and systems. This was a skill set that participants acknowledged to be rare across Canadian police services, while also insisting on the growing need for these skills. Additionally, given the interconnection of police services, an individual service must not be seen as a "weak link."

\section{Protecting Information}

The group discussion on the emerging role of the CISO within police services gave rise to the growing awareness that community and officer safety is dependent on the timely sharing of information. "Information is the lifeblood of policing [and] therefore we must make the most of the masses of data made available to us enabling intelligence-led preventative policing and investigation, while continuing to meet citizen expectations regarding how we handle their data" (National Police Technology Council, 2020, p. 2).

To be successful and maintain the trust of partners and the community they serve, police services must protect their information against ever-increasing cyber threats. The growing attack surface, mobile environment, and maturing attacker capabilities greatly increase the threats facing a police service. In the same way that police services prepare for a broad spectrum of threats that they face in their policing duties, they must prepare for the potential of cyber incidents. At a minimum, a police service should:

understand the cyber threats they are facing;

use a risk-based approach to assess the effectiveness of their cyber program;

communicate the cyber program to command staff and board; and

- integrate cyber in all new Information Management (IM)/IT initiatives.

This also requires the police service executive leadership to have a basic level of knowledge of the challenges facing their IT unit, and the threats/risks to the service from cyber attacks. This level of understanding has a direct impact on the service's ability to align technology initiatives to policing outcomes by ensuring that the cyber risks are also evaluated. To effectively do this, the service must embrace an approach that continuously manages risk to their information assets. It is recommended that they embrace a methodology to "planbuild-run" for their cyber program (Fig. 1).
The complexity of the environment in which we operate is increasing daily. The police service must be resilient and open to new methods of operation. As the reliance on third-party providers (cloud-based solutions, software as a service [SaaS], solution providers) increases and resources are constrained, organizations are looking for innovative ways to close the seemingly inevitable skills gap.

Only by measuring program effectiveness, understanding the threats and implementing a programmatic way forward can a police service responsibly manage and protect its information assets.

\section{Innovation and Technology}

The discussion among these former police leaders inevitably led to a discussion of innovation and technology, and the rationale for both. It is important to define the distinction between these two areas, as in today's environment there is frequently confusion and overlap between them, where innovation is perceived to involve technology and technology is perceived to be innovative.

Several authors helped guide the discussions on innovation, and we shall draw upon two prominent authors in this arena who provide that "innovation [is] a process which brings some new method into an organization" (Green \& King, 2000, p. 305) or innovation is "an idea, practice or object that is perceived as new by the individual or other unit of adoption" (Rogers, 2003, p. 12).

Green and King (2000) group innovation into four principal categories:

Radical innovations require massive restructuring or changes in the organization.

- Administrative innovations change the management of the organization.

- Technical innovations change the hardware used to produce a service or product.

- Program innovations require new units or operations to meet an organizational goal.

While other authors have identified the need for innovation to be "best in the field," neither Rogers nor Green and King required a concept, practice, or idea to necessarily improve an existing practice or process; rather it simply needed to be new to meet the criteria of being innovative. This underscores the view of the discussion group, which emphasized the need to understand the problem that technology was supposed to solve, and the test that new technology needed to help the community being served. For today's police leaders, it is important to evaluate new technology opportunities against these criteria, mindful that technology innovations may be new to the organization, but they may not necessarily be an improvement over existing practices.

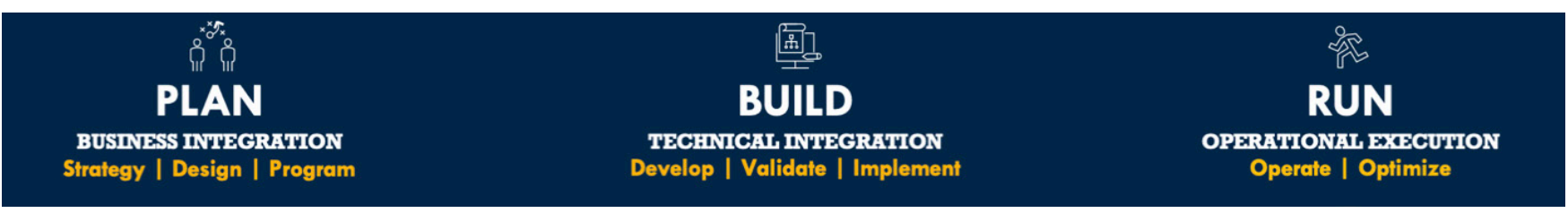

FIGURE 1 "Plan-build-run." This approach ensures continuous management of risk to information assets, allowing technology initiatives to align with policing outcomes. 


\section{Issues that Were Raised in U.S.-Centric Discussions}

It is also worth examining issues that have been identified in other literature, research, and reviews of this topic, that were absent from this discussion.

The most significant of those pertained to technology adoption. In studies focused on the United States, the question of organizational adoption was addressed. This included not only the likelihood of personnel using the new technology, but also the issue of how to incentivize personnel to use it. "Overall, a novel finding from this work is that reducing barriers that prevent effective and efficient adoption seems to be one of the strongest mechanisms for improving police buy-in" (Egnoto et al., 2017, p. 314). Further, Egnoto found in his study, which examined the use of personal radiation detectors, that:

[a]dditional findings from this work are how effective incentives need to focus on streamlining devices into the officers' lives. Unlike numerous other diffusion pieces which emphasize visibility or other forms of compensation, this investigation emphasizes ease of use not only to accomplish the designated task but a desire among officers for ease of use for new technologies to go beyond their primary purpose and make other existing tasks more manageable. This may imply a saturation point of technology adoption among police officers, who are already encumbered with a multitude of technologies. Adding a new one because it is better at performing an existing task is no longer sufficient motivation, and devices need to now fit into a broader context of lifestyle contributions within officers' lives. (Egnoto et al., 2017, pp. 314-315)

Both the authors of the current study have found that technology adoption is a significant challenge within the policing environment. None of the participants identified this as a significant point when technology is being considered for implementation, nor as a noteworthy success or failure during their tenure within their respective policing services. It is the authors' opinion that the issue of technology adoption becomes significantly less imposing when the six pillars of focus are effectively addressed, especially managing key stakeholder expectations.

\section{DISCUSSION}

How do we harness the power of digital, data and technology to better protect the communities we serve?

Based on our discussion with police leaders, there are some foundational requirements to effectively implement secure, timely, and relevant technology solutions in support of policing. Police leaders must be engaged in supporting underlying needs at the command level, which evolve into technology-driven initiatives. Police services are at a crucial point given the number of external factors they must manage today. Our discussions raised the following key points.

\section{Strategic Alignment}

Strategic alignment was the most significant topic among this discussion group, and it is a continuous theme in literature on this topic. The overarching concern from all participants was the need to ensure that technology acquisition was aligned with an organization's vision. The Strom research in this area from 2017 found that this was consistently lacking in police agencies across the United States. Police services must deal with their existing or legacy environment, the migration to new environments (such as moving from on-premises information storage to cloud storage) as well as the move to new capabilities. It was a foundational point to the discussion that any technology initiative must be aligned with the needs of the service and their partners, and that technology should not be deployed without demonstrated value to policing. Finally, a technology plan (strategic) must be aligned with the service and have full visibility and the support of the command staff, and the technology plan must include an assessment of information assets and outline the protection of information.

\section{Public Expectations-Ethical Considerations}

A major concern for the discussion participants was the ethical application of technology, and the need to not only "test" new technology against community expectations, but to determine whether the technology being acquired poses any ethical dilemmas for the police service or its members. The technology acquisition process needs to include an examination of community expectations and determine whether the technology's capability would be considered appropriate by the community. The inclusion of this process is a significant shift from the Strom research, which did not include an evaluation of ethical considerations related to the acquisition or implementation of technology. The public has expectations on how a police service safeguards information and on the ethical use of information holdings. The service must be willing to discuss its ability to risk-manage the integrity of its information holdings and how it is using advanced analytics/artificial intelligence to carry out its mission in an ethical way.

\section{Command Staff Engagement}

The participants also emphasized the role of the chief and the command team in ensuring that new technology will perform a needed function. They identified that it was the role of the command team to ask questions about the validity of the technology and its requirement.

Do new weapons make policing safer or more effective? Will DNA testing be cost-effective for the average police agency? Can automobile vehicle locator systems be used to increase the value of police patrol? These questions, which seem so obviously central to the question of adoption of new technologies, are seldom examined in policing. (Weisburd \& Neyroud, 2011, p. 7)

Command staff must commit to investing in themselves and their staff to equip members of their services with the right knowledge, skills, and tools to deal with the increasingly complex environment in which they operate. This includes ensuring not only that adequate technology resources are available, but that those resources align with the technology needs and technology projects of the Service. 


\section{CONCLUSION}

The authors endeavoured to engage Canadian police leaders in a discussion on technology to provide thoughts, insight, and guidance to the police leaders of tomorrow. We are hopeful that this analysis will provide some areas of focus for police executives, and even a checklist for organizations to undertake when new technology projects are being considered. We are hopeful that this work assists police services and the communities they serve in the effective acquisition and use of new technology.

CONFLICT OF INTEREST DISCLOSURES

The authors have no conflicts of interest to declare.

AUTHOR AFFILIATIONS

* Department of criminology, Ontario Tech University, Oshawa, ON, Canada; ${ }^{+}$Optiv Security, Denver, CO, USA.

\section{REFERENCES}

Egnoto, M., Ackerman, G., Iles, I., Liu, B. F., \& Behlendorf, B. (2017). What motivates the blue line for technology adoption? Insights from a police expert panel and survey. Policing: An International Journal, 40(2), 306-320. doi:10.1108/PIJPSM-03-2016-0031

Green, B., \& King, W. R. (2000). Measuring police innovation: issues and measurement innovation. Policing: An International Journal of Police Strategies and Management 23(3), 303-317. doi:10.1108/13639510010342994

National Police Technology Council. (2020). National Digital Policing Strategy 2020-2030. National Police Chiefs Council, Association of Police and Crime Commissioners. London.

Rogers, C., \& Scally, E. J. (2017). Police use of technology: insights from the literature. International Journal of Emergency Services, 7(2). doi:10.1108/IJES-03-2017-0012

Rogers, E. (2003). Diffusion of innovation (5th ed.). Free Press.

Strom, K., RTI International, \& Police Executive Research Forum. (2017). Research on the Impact of Technology on Policing Strategy in the 21st Century. Washington, DC: National Institute of Justice.

Weisburd, D., \& Neyroud, P. (2011). New Perspectives in Policing Police Science: Toward a new paradigm. Washington, DC: National Institute of Justice. 